\title{
Herbivores mediate different competitive and facilitative responses of native and invader populations of Brassica nigra
}

\author{
Ayub M. O. Oduor, ${ }^{1,3}$ Sharon Y. Strauss, ${ }^{2}$ Yedra García, ${ }^{1}$ Modesto Berbel Cascales, ${ }^{1}$ \\ AND José M. Gómez ${ }^{1}$ \\ ${ }^{1}$ Departamento de Ecología, Universidad de Granada, E-18071 Granada, Spain \\ ${ }^{2}$ Section of Evolution and Ecology, One Shields Avenue, University of California, Davis, California 95616 USA
}

\begin{abstract}
Differences in plant and herbivore community assemblages between exotic and native ranges may select for different levels of plant traits in invasive and native populations of plant species. Little is currently known of how herbivores may mediate competitive and facilitative interactions between invasive and native populations of plant species and their plant neighbors. Here, we conducted a common-garden field experiment to test whether invasive and native populations of Brassica nigra differ in phenotypic expressions of growth (biomass and plant height) and reproductive (seed yield) traits under different plant neighbor treatments and ambient vs. reduced level of insect herbivore damage on the B. nigra plants. We found significant interactive effects of plant neighbor treatments, level of insect herbivore damage on $B$. nigra plants, and invasive status of $B$. nigra on the phenotypic trait expressions. Plant neighbor treatments had minimal effects on phenotypic trait expressions by invasive populations of $B$. nigra under either level of insect herbivore damage. In contrast, for native populations of $B$. nigra, ambient level of insect herbivore damage resulted in plant neighbors facilitating expression of the traits above, while reduced damage resulted in plant neighbors competitively suppressing trait expression. Our results suggest that insect herbivores and plant neighbors interactively shape expression of plant traits in native and exotic ranges of invasive plants. Such interactions could potentially lead to different selection pressures on traits that determine antiherbivore defenses and plant-plant interactions.
\end{abstract}

Key words: Brassica nigra; common garden; competition; conspecific interaction; enemy release hypothesis (ERH); evolution of increased competitive ability (EICA); facilitation; herbivory; heterospecific; invasive species; native populations; rapid evolution.

\section{INTRODUCTION}

Interactions between plants often involve both competition and facilitation (Bertness and Callaway 1994, Callaway and Walker 1997). Mechanisms of competition and facilitation often operate simultaneously within the same plant community or even between a pair of interacting individual plants; the net outcome (competition or facilitation) is influenced by abiotic and biotic conditions, including level of herbivore damage (Callaway and Walker 1997). According to the stress-gradient hypothesis, the significance of facilitation of a focal plant by its plant neighbor may increase with the level of stress (e.g., high herbivore damage) because plant neighbors may ameliorate the negative effects of such stress (Callaway and Walker 1997). Conversely, significance of compet-

Manuscript received 18 November 2012; revised 20 March 2013; accepted 11 April 2013. Corresponding Editor: D. F. Doak.

${ }^{3}$ Present address: International Ecosystem Management Partnership-United Nations Environment Programme (UNEP-IEMP), c/o Institute of Geographic Sciences and Natural Resources Research (IGSNRR), Chinese Academy of Sciences, 11A Datun Road, Chaoyang District, Beijing 100101 China. E-mail: ayub.oduor@unep-iemp.org

Konstanzer Online-Publikations-System (KOPS)

URL: http://nbn-resolving.de/urn:nbn:de:bsz:352-256305 itive interactions between plants may increase under a low level of stress (e.g., reduced herbivore damage) (Callaway and Walker 1997).

Intraspecific genetic variations in phenotypic expressions of growth, reproductive, and defensive traits by plants enable the plants to respond to selection imposed by herbivores and plant neighbors (Strauss et al. 2006, Vellend 2006, Lankau and Strauss 2007, Johnson et al. 2008, Lankau 2008, Leger and Espeland 2010, Willis et al. 2010, Goergen et al. 2011, Agrawal et al. 2012, Züst et al. 2012). Numerous invasive plant species interact with different community assemblages of herbivores (Liu and Stiling 2006) and plant neighbors (Callaway and Aschehoug 2000, Maron et al. 2004, Bossdorf et al. $2005)$ in their exotic vs. native ranges. Using a metaanalysis, Liu and Stiling (2006) show that invasive plant species typically experience lower insect damage levels, interact with fewer individuals and species of herbivores and relatively more generalist vs. specialist herbivore species in their exotic ranges than in their native ranges (Liu and Stiling 2006). These differences in herbivore and plant community assemblages between the exotic and native ranges of plants may impose different selection pressures on plant traits. Hence, invasive and native populations of the same plant species may express 
TABLE 1. Brassica nigra seed sources for the experiment described.

\begin{tabular}{|c|c|c|c|c|}
\hline Population & Country/state of origin & $\begin{array}{l}\text { Accession number } \\
\text { or collector's name }\end{array}$ & $\begin{array}{l}\text { Geographic } \\
\text { region }\end{array}$ & $\begin{array}{c}\text { Invasive } \\
\text { status }\end{array}$ \\
\hline 1 & McLaughlin Reserve, Lake County, California, USA & R. Lankau & North America & invasive \\
\hline 2 & Napa County, California, USA & R. Lankau & North America & invasive \\
\hline 3 & UC Davis airport (Yolo County), California, USA & S. Y. Strauss & North America & invasive \\
\hline 4 & Puerto Real (Cádiz), Spain & J. M. Gómez & Mediterranean & native \\
\hline 5 & France & CR 2113 & Mediterranean & native \\
\hline 6 & Doorweth, Gelderland, The Netherlands & M. Macel & Central Europe & native \\
\hline
\end{tabular}

Note: All six populations were field collected, except for that from France, which was obtained from a germ plasm collection.

different levels of growth, reproductive, and defensive traits (e.g., Blossey and Nötzold 1995, Callaway and Aschehoug 2000, Buckley et al. 2003, Leger and Rice 2003, Maron et al. 2004, Müller-Scharer et al. 2004, Stastny et al. 2005, Whitney and Gabler 2008, Zou et al. $2008 a, b$, Oduor et al. 2011). One way of inferring postintroduction evolutionary changes in phenotypic trait expressions by invasive plant species involves growing invasive and native populations of the same plant species under similar conditions, then quantifying differences in mean trait values between the two groups of plants (Maron et al. 2004).

Herbivore-driven evolution and expression of antiherbivore defensive traits, namely resistance and tolerance, by focal plants can influence competitive or facilitative interactions between the focal plants and their plant neighbors (Louda et al. 1990, Rand 2004, Thelen et al. 2005). Through resistance, damage by herbivores on a focal plant may induce expression of high levels of antiherbivore allelochemicals that, in turn, suppress the growth of plants that are neighbors of the focal plant (Callaway et al. 1999, Thelen et al. 2005, Lankau and Kliebenstein 2009). Through tolerance (i.e., a measure of compensatory growth after herbivore damage), herbivores may influence both competitive and facilitative interactions between plants (Callaway et al. 1999, Rand 2004). High tolerance of herbivore damage may be associated with increased growth rate and enhanced resource use by focal plants following herbivore damage (Callaway et al. 1999, 2006). Hence, a focal plant expressing high tolerance after herbivore damage may have an enhanced competitive ability against its plant neighbors (Callaway et al. 1999, 2006). On the other hand, plant neighbors can enhance (i.e., facilitate) a focal plant's tolerance of herbivore damage by ameliorating environmental stresses that might otherwise limit compensatory growth of the focal plant (Rand 2004).

An increasing number of experiments test for the effects of plant neighbors on phenotypic expressions of growth and reproductive traits by invasive and native populations of plant species (e.g., Vilà et al. 2003, Bossdorf et al. 2004a, McKenney et al. 2007, Ridenour et al. 2008, Zou et al. 2008a, He et al. 2009, Leger and Espeland 2010). However, none of those experiments has tested for the joint effects of herbivore damage and plant neighbors on the phenotypic expression of those traits. The objective of the current experiment, therefore, was to test for the joint effects of insect herbivory and plant neighbors on phenotypic expressions of growth and reproductive traits by invasive and native populations of Brassica nigra in the field. Specifically, we asked: Do invasive and native populations of $B$. nigra differ in phenotypic expressions of growth and reproductive traits in the presence vs. absence of plant neighbors and under ambient vs. reduced levels of insect herbivore damage?

\section{Materials And Methods}

\section{Study system}

Brassica nigra (L.) Koch (Brassicaceae) is an annual herb native to the Mediterranean region and North Africa that has spread widely across the globe (Bell and Muller 1973, Feeny and Rosenberry 1982). In North America, invasive populations of B. nigra have likely arisen from multiple sources introduced $\sim 200$ years ago (Westman and Kresovich 1999). In North America, B. nigra can form thick, monospecific stands, generally in disturbed areas such as roadsides (Lankau and Strauss 2008).

\section{Experimental design and setup}

Seeds from three introduced (Californian) and three native (Mediterranean region and European) populations of B. nigra were field-collected by the authors or collaborators, or obtained from a seed germ plasm collection (see Table 1 for details). Seeds obtained from a germ plasm collection had bee collected directly from wild populations in the field and were then grown for one generation only in common glasshouses to remove maternal effects. Because B. nigra occurs in many localities within its native and invasive ranges, it would have been desirable to use numerous distinct populations of the plant from either range. However, here we used only three distinct populations from either range due to the large nature of the experiment (39 treatments $\times 20$ replications). Furthermore, we used only the populations from California to represent invasive range, because seeds from those populations had higher germination percentages than seeds obtained from other regions of North America. In addition, we obtained seeds of four heterospecific species (two species each for 
legumes and grasses) from a commercial seed dealer (Rocalba SA, Barcelona, Spain). The legumes were Vicia sativa and Medicago sativa, while the grasses were Lolium perenne and Dactylis glomerata. Each of these four heterospecific species is widely distributed, cooccurring with $B$. nigra in its native as well as exotic range, including in most or all counties in California (The Jepson Interchange, information available online). ${ }^{4}$ As seeds of the four heterospecific species used presently were not collected from a source population of the six $B$. nigra populations studied here, there were no opportunities for co-adaptations to have occurred between the $B$. nigra populations and the heterospecific species.

Seeds of all the six $B$. nigra populations and the four heterospecific species were sown in a commercial potting substrate (dry matter, 60-62\%; total organic matter, 7476\%; pH, 5.2-5.5; electrical conductivity, 0.4-0.5 S; nitrogen, $100-150 \mathrm{mg} / \mathrm{L} ; \mathrm{P}_{2} \mathrm{O}_{5}, 150-200 \mathrm{mg} / \mathrm{L} ; \mathrm{K}_{2} \mathrm{O}$, 200-250 $\mathrm{mg} / \mathrm{L}$; total pore space, $85-90 \%$ ) in plastic plug-trays with a volume of $16.7 \mathrm{~cm}^{3} /$ cell in a glasshouse at the end of March 2009. The resulting seedlings were raised under glasshouse conditions for two weeks (under natural lighting and temperature conditions). At two weeks, seedlings were transplanted into a native range field plot in Granada, southeastern Spain $\left(37^{\circ} 10^{\prime} 30^{\prime \prime} \mathrm{N}, 03^{\circ} 38^{\prime} 10^{\prime \prime} \mathrm{W}\right.$; see Plate 1$)$. We grew these plants employing a fully factorial design with three main factors: invasive status of B. nigra (two levels), plant neighbor treatment (three levels), and herbivore damage (two levels). A seedling from each of the six populations of B. nigra was grown with one of three types of plant neighbors (alone without a plant neighbor, with a heterospecific neighbor, or with a conspecific neighbor) and under one of two levels of herbivore damage (ambient level of damage or reduced level of damage).

For the Alone neighbor treatment, an individual $B$. nigra plant was grown in the absence of any plant neighbor, yielding six Alone neighbor treatments. For $B$. nigra plants grown together with a heterospecific plant neighbor, an individual $B$. nigra plant was grown in a pairwise combination with an individual plant from each of the four heterospecific species, yielding 24 heterospecific neighbor treatments. For conspecific neighbor treatments, an individual B. nigra plant from each of the three native populations was grown in a pairwise combination with a randomly selected individual plant from each of the three invasive populations of $B$. nigra. This resulted in nine conspecific plant neighbor treatments. In total, there were 39 plant neighbor treatments (i.e., 24 heterospecific +9 conspecific +6 Alone), with each treatment being replicated 20 times. Each of the 39 plant neighbor treatments was assigned at random to a position within 20 separate planting rows, with each row being a complete replicate. The experimental design employed was a completely randomized design (CRD).

${ }^{4}$ http://ucjeps.berkeley.edu/interchange/
The plant neighbor treatments were spaced $70 \mathrm{~cm}$ apart within a row, while the rows were spaced $100 \mathrm{~cm}$ apart. The transplanted seedlings were watered regularly until they established, after which watering frequency was fixed at twice a week until the plants matured.

One-half of all the plants in the experiment was released from the ambient level of herbivore damage using an insecticide. The remaining half was treated with water only (control). Both the focal B. nigra plants and their plant neighbor in the respective plant neighbor treatments received the insecticide and water treatments, accordingly. The effects of herbivores on plant growth and reproduction can vary with the stage at which a plant is damaged by herbivores (e.g., seedling vs. adult stage) (Maschinski and Whitham 1989). In the current experiment, however, we did not stagger insecticide spray according to the different growth stages of $B$. nigra. The insecticide and water control treatments were applied weekly. Every other row was treated with a broad-spectrum insecticide, CHAS 48 EC (Cheminova, Madrid, Spain), at a rate of $0.5 \mathrm{~mL}$ per liter of water. A narrow-swath sprayer was used to ensure that the insecticide could be directed at plant leaves only, hence avoiding interference with pollinators that visited flowers of the same plants. In a field experiment that we conducted a year earlier in a separate location (Cadiz, southwestern Spain, 36 $31^{\prime} \mathrm{N}, 6^{\circ} 11^{\prime} \mathrm{W}$ ) using a larger sample of invasive and native populations of $B$. nigra (including the five we used here), the same insecticide significantly reduced leaf damage on invasive and native populations of B. nigra by $19 \%$ and $20 \%$, respectively (Oduor et al. 2011). Based on data from the previous experiment and focusing only on the populations used commonly in the previous as well as present experiment, the reductions in leaf damage were $28 \%$ for the three invasive populations and $26 \%$ for two of the three native populations. (There was one new native population in this experiment not included in our previous one; see Appendices A and B). Those percentage reductions in insect herbivore damage significantly improved growth performances of invasive and native populations of B. nigra (Oduor et al. 2011). In the current experiment, we repeated the identical insecticide treatment, but did not quantify percentage reduction in leaf damage by the insecticide. In the course of repeated qualitative censuses of herbivores to identify the generalist and specialist herbivores of $B$. nigra occurring at the current experimental site (see Appendix C), it was noted that the insecticide spray greatly reduced herbivore load on the insecticide-treated plants compared to the control plants.

The experimental plot was weeded regularly to avoid undesirable interference from unwanted plant neighbors. This was accomplished by removing any plant that occurred within a radius of $20 \mathrm{~cm}$ around the plant neighbor treatments. From the current experiment, any noted significant differences between the invasive and native populations of $B$. nigra in phenotypic trait 
expressions would be an indicator of post-introduction trait evolution by invasive populations of B. nigra.

\section{Measurement of expressed traits}

Plants were harvested individually as they matured (from approximately the fourth month following the date of transplanting), after which the following four measures of growth and reproductive traits were quantified for each individual plant: plant biomass (root + shoot) (in grams), seed yield separated into two categories (total seed number and biomass of seeds), and plant height (centimeters). Seed number per plant was estimated by multiplying total fruit count per plant with mean seed number per fruit. Mean seed number per fruit was computed from six randomly selected fruits per plant. Total seed biomass produced by an individual plant was estimated by multiplying seed number per plant by mean biomass of individual seeds computed from the same six fruits just described. Plant biomass was obtained by oven-drying shoots and roots of each plant at $65^{\circ} \mathrm{C}$ for 15 hours and then weighing them together. Plant height was obtained by measuring the length between root collar and the uppermost part of a shoot.

To explore the effects of plant neighbors on phenotypic trait expressions by native and invasive populations of B. nigra (through competition or facilitation), we used the metric relative interaction intensity (RII), whose values range from -1 to 1 (Armas et al. 2004). A focal plant with a negative RII value is one whose growth/reproductive output has been competitively suppressed by its plant neighbor, while a focal plant with a positive RII value is one whose growth/ reproductive output has been facilitated by its plant neighbor (Armas et al. 2004). RII is calculated as: $\left(F_{\mathrm{W}}-\right.$ $\left.F_{\mathrm{O}}\right) /\left(F_{\mathrm{W}}+F_{\mathrm{O}}\right)$, where $F_{\mathrm{W}}$ is the performance of a focal plant in the presence of a plant neighbor, and $F_{\mathrm{O}}$ is the performance of a focal plant in the absence of a plant neighbor (Armas et al. 2004). The RII values were computed separately for the conspecific and heterospecific plant neighbor treatments under either level of herbivore damage. This was done for each of the four growth and reproductive traits previously described. To address a problem of lack of statistical independence of scores from plants grown in pairwise combinations, we used scores from only half of the plants involved in those pairwise combinations. For example, when 20 plants from an invasive population were grown together with 20 plants from a native population, then scores of only 10 randomly selected plants from that invasive population (denominated focal plants) were used in the analyses. Scores of plants from the native population that had been grown in those pairwise combinations were discarded. A similar technique was applied for native populations of $B$. nigra. For $B$. nigra plants grown in pairwise combinations with a heterospecific plant neighbor, we included scores from all of the $B$. nigra plants, while discarding scores for all the heterospecific plant neighbors.

\section{Statistical analyses}

We first performed a permutational multivariate analysis of variance (PERMANOVA) to test for the main and interactive effects of plant neighbor treatment, level of herbivore damage, and invasive status of $B$. nigra on phenotypic expressions of the four growth and reproductive traits combined. For this analysis, the ADONIS function in library VEGAN was used ( $R$ Development Core Team 2009). We then ran Generalized Linear Mixed Models (GLMMs) in univariate analyses of variance to test for the main and interactive effects of the same three independent variables (effects) on phenotypic expressions of the growth and reproductive traits by invasive and native populations of B. nigra. We developed eight candidate models (including a null model with the intercept only) for each of the four growth and reproductive traits. The models contained all possible combinations of main effects of plant neighbor treatment, level of herbivore damage, and invasive status of B. nigra as well as their two- or threeway interactions. In the same models, we included the following as random-effects independent variables: the population of origin of $B$. nigra nested within invasive status of B. nigra, and the species identity of the heterospecific plant neighbor nested within plant neighbor treatment. These GLMMs were run using two sets of scores: absolute scores of phenotypic trait expression, and the RII scores computed from the absolute scores, as explained in Measurement of expressed traits. We used Akaike's information criterion (AIC), corrected for small sample size $\left(\mathrm{AIC}_{\mathrm{c}}\right)$, to determine the bestsupported model for each of the four growth and reproductive traits. The best-supported model was the one with the lowest $\mathrm{AIC}_{\mathrm{c}}$ value (Zuur et al. 2009). All analyses were performed with package lme4 in R ( R Development Core Team 2009, Bates et al. 2012). We used pairwise REML contrasts (Bates 2011) to compare phenotypic trait expressions by invasive and native populations of $B$. nigra under all plant neighbor treatments and both levels of herbivore damage to better understand the significance of the complex interactions.

\section{Results}

Interactive effects of level of herbivore damage and plant neighbor treatments on phenotypic trait expressions by native and invasive populations of $\mathrm{B}$. nigra

The result of the PERMANOVA revealed a significant three-way interactive effect of the plant neighbor treatment, level of herbivore damage, and invasive status of B. nigra on phenotypic expressions of growth and reproductive traits by the invasive and native populations of B. nigra (Table 2). Similarly, for the univariate GLMMs, the models that best explained variations in the growth and reproductive traits ex- 
TABLE 2. Permutational multivariate analysis of variance (PERMANOVA) testing for the main and interactive effects of plant neighbor treatment, level of herbivore damage, and invasive status of Brassica nigra on phenotypic expressions of four growth and reproductive traits by the invasive and native populations of $B$. nigra.

\begin{tabular}{lrrrc}
\hline \hline \multicolumn{1}{c}{ Source } & df & SS & $F$ & $P$ \\
\hline Plant neighbor & 3 & 1.11 & 2.52 & 0.019 \\
Herbivore damage & 1 & 0.41 & 2.79 & 0.068 \\
Invasive status & 1 & 4.80 & 32.50 & 0.001 \\
Plant neighbour $\times$ herbivore damage & 3 & 1.06 & 2.40 & 0.022 \\
Plant neighbour $\times$ invasive status & 3 & 0.32 & 0.72 & 0.65 \\
Herbivore damage $\times$ invasive status & 1 & 0.49 & 3.35 & 0.026 \\
Plant neighbour $\times$ herbivore damage $\times$ & 3 & 1.19 & 2.70 & 0.01 \\
$\quad$ invasive status & 730 & 107.84 & & \\
Residuals & 745 & 117.24 & & \\
Total & & &
\end{tabular}

pressed by invasive and native populations of $B$. nigra were those in which there were three-way interactions among levels of herbivore damage, plant neighbor treatment, and invasive status of B. nigra (Table 3). When grown alone without any plant neighbor and under reduced level of herbivore damage, native populations of $B$. nigra produced significantly higher plant biomass, seed number, and seed biomass than invasive populations of $B$. nigra (Fig. 1). The native populations of $B$. nigra experienced a greater relative increase in plant height than invasive populations of $B$. nigra under reduced herbivore damage, despite the fact that, overall, invasive populations were always taller than native populations (Fig. 1). Under ambient levels of herbivore damage and in the absence of a plant neighbor, invasive populations of $B$. nigra produced significantly higher total plant biomass and seed number per plant than native populations of B. nigra (Fig. 1). However, in the presence of any plant neighbor and under ambient level of herbivore damage, native and invasive populations of $B$. nigra yielded similar amounts of seeds and total plant biomass (Fig. 1). Grass and legume heterospecific neighbors had differential effects on invasive and native populations of B. nigra when the level of herbivore damage was reduced. Native populations produced significantly less seed biomass than invasive populations of $B$. nigra when grown with grass neighbors, but significantly more plant biomass when grown with legume neighbors (Fig. 1).

\section{Interactive effects of level of herbivore damage and plant neighbors on relative interaction intensity (RII)}

The patterns of phenotypic expression of growth and reproductive traits by invasive and native populations of B. nigra under different levels of herbivore damage and plant neighbor treatments can be further elucidated and summarized with the RII metric. The RII metric takes into account phenotypic trait expression by a focal plant in the absence vs. presence of a plant neighbor. Based on the RII, variations in plant biomass and seed yields by

TABLE 3. Generalized linear mixed-effects models (GLMMs) fitted to test for the main and interactive effects of plant neighbor treatment, level of herbivore damage, and invasive status of Brassica nigra on phenotypic expressions of four growth and reproductive traits by the invasive and native populations of $B$. nigra.

\begin{tabular}{|c|c|c|c|c|c|c|c|c|}
\hline \multirow[b]{2}{*}{ Model } & \multicolumn{4}{|c|}{$\mathrm{AIC}_{\mathrm{c}}$ values computed from absolute scores } & \multicolumn{4}{|c|}{$\mathrm{AIC}_{\mathrm{c}}$ values computed from RII scores } \\
\hline & $\begin{array}{l}\text { Plant } \\
\text { height }\end{array}$ & $\begin{array}{c}\text { Plant } \\
\text { biomass }\end{array}$ & $\begin{array}{l}\text { Number } \\
\text { of seeds }\end{array}$ & $\begin{array}{c}\text { Seed } \\
\text { biomass }\end{array}$ & $\begin{array}{l}\text { Plant } \\
\text { height }\end{array}$ & $\begin{array}{c}\text { Plant } \\
\text { biomass }\end{array}$ & $\begin{array}{l}\text { Number } \\
\text { of seeds }\end{array}$ & $\begin{array}{c}\text { Seed } \\
\text { biomass }\end{array}$ \\
\hline Plant neighbor & 6919.78 & 5754.37 & 14248.12 & 5577.44 & -176.44 & 29.13 & 66.56 & 102.23 \\
\hline Herbivore damage & 6901.47 & 5754.27 & 14267.64 & 5576.65 & -190.13 & 5.53 & 40.73 & 84.05 \\
\hline Invasive status & 6916.88 & 5754.40 & 14272.56 & 5579.17 & -186.95 & 23.38 & 61.66 & 98.41 \\
\hline $\begin{array}{l}\text { Plant neighbor } \times \text { herbivore } \\
\text { damage }\end{array}$ & 6883.51 & 5738.62 & 14181.22 & 5567.48 & -159.73 & 24.46 & 58.77 & 98.54 \\
\hline $\begin{array}{l}\text { Plant neighbor } \times \text { invasive } \\
\text { status }\end{array}$ & 6898.06 & 5745.49 & 14194.34 & 5572.08 & -157.96 & 44.02 & 79.53 & 114.93 \\
\hline $\begin{array}{l}\text { Herbivore damage } \times \\
\text { invasive status }\end{array}$ & 6883.25 & 5739.08 & 14238.08 & 5575.10 & -184.71 & -21.55 & 21.78 & 72.00 \\
\hline $\begin{array}{l}\text { Plant neighbor } \times \text { herbivore } \\
\text { damage } \times \text { invasive } \\
\text { status }\end{array}$ & 6828.94 & 5699.63 & 14059.17 & 5550.30 & -130.36 & 16.03 & 53.81 & 99.69 \\
\hline
\end{tabular}

Notes: The models were run using absolute scores of the phenotypic traits as well as relative interaction intensity index (RII) scores computed from the absolute scores (see explanations in Materials and methods). Model selection was based on the Akaike's information criterion corrected for small sample size $\left(\mathrm{AIC}_{\mathrm{c}}\right)$. The best-supported model had the lowest $\mathrm{AIC}_{\mathrm{c}}$ value, highlighted in boldface type. In each model, the following were included as random-effects independent variables: (a) the population identity of $B$. nigra nested within invasive status of B. nigra, and (b) the species identity of the heterospecific plant neighbor nested within plant neighbor treatment. 

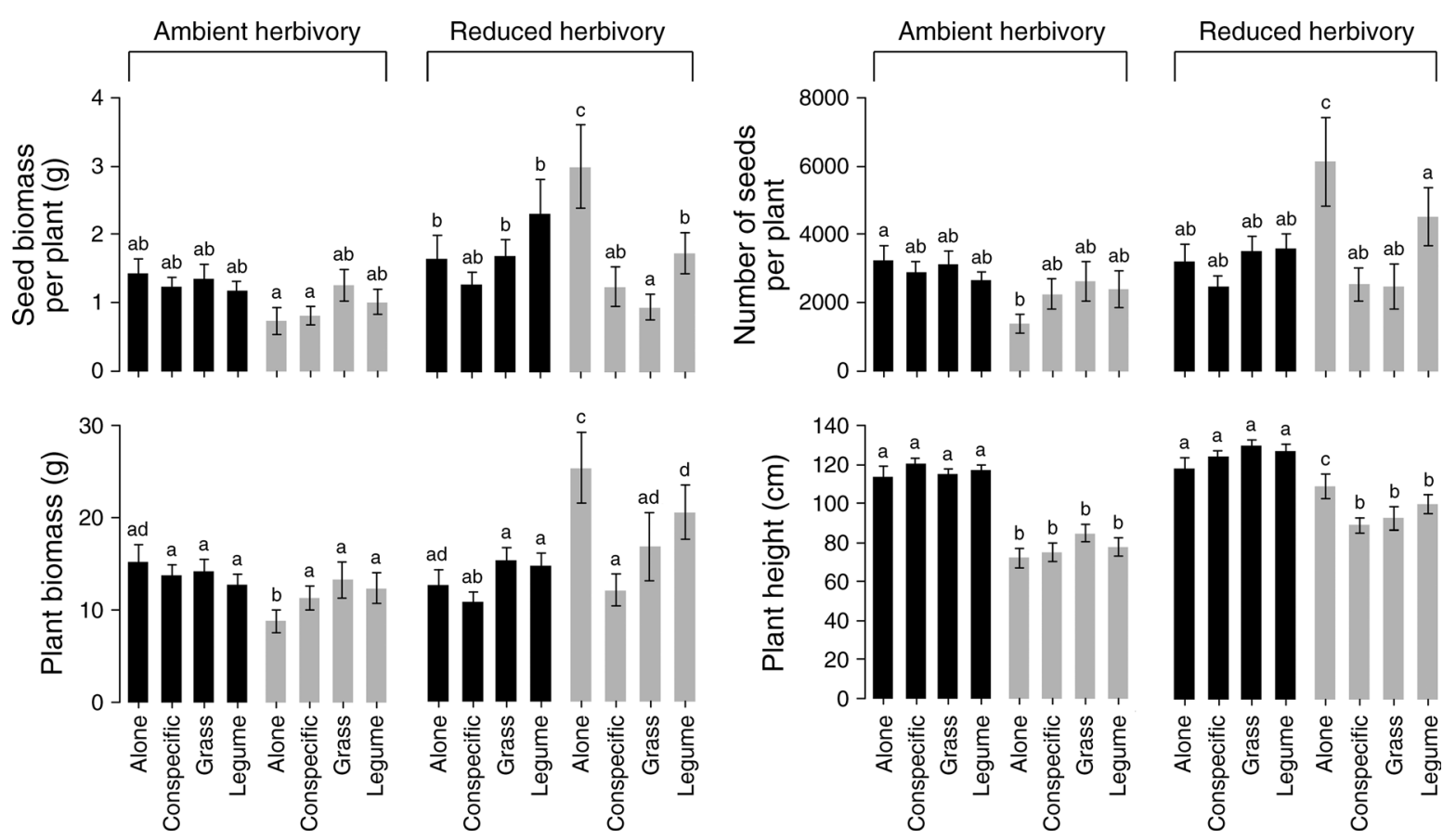

FIG. 1. Mean ( \pm SE) phenotypic trait expressions by invasive (black bars) and native (gray bars) populations of Brassica nigra under two levels of insect herbivore damage (ambient herbivory vs. reduced herbivory) and three plant neighbor treatments: alone, conspecific, and heterospecific (grass and legume). Lowercase letters above bars indicate statistical significance: means that share a letter are not significantly different from each other $(P>0.05)$.

the invasive and native populations of $B$. nigra were best explained by the models in which there were two-way interactions among levels of herbivore damage and invasive status of B. nigra (Table 3). On the other hand, variations in plant height were best explained by the main effect of level of herbivore damage (Table 3). The seed yield by invasive populations of $B$. nigra were mostly unaffected (the RII values are not significantly different from zero) by heterospecific plant neighbors under either level of herbivore damage (Fig. 2). The grass and legume heterospecific neighbors facilitated biomass yield of invasive populations of $B$. nigra under reduced level of herbivore damage (Fig. 2). All three types of plant neighbor treatment facilitated expression of plant height by invasive populations of B. nigra under reduced or ambient level of herbivore damage (Fig. 2). In contrast, for the native populations of B. nigra, the conspecific and heterospecific plant neighbors competitively suppressed phenotypic expressions of all four traits under reduced herbivore damage (Fig. 2). Under the ambient level of herbivore damage, however, the plant neighbors (mostly heterospecific) facilitated phenotypic trait expressions by the native populations of $B$. nigra (Fig. 2).

\section{DisCusSion}

We found that the level of insect herbivore damage and plant neighbor treatment interacted to affect phenotypic expression of growth and reproductive traits by invasive and native populations of $B$. nigra differently. In general, the plant neighbors affected (through facilitation and competition) the native populations of B. nigra more strongly than the invasive populations of B. nigra under either level of insect damage (Fig. 2). Heterospecific plant neighbors (grasses and legumes) competitively suppressed seed yield by native populations of $B$. nigra, while having no significant effect on seed yield by invasive populations of B. nigra under a reduced level of herbivore damage (Fig. 2). Under ambient level of herbivore damage, the heterospecific plant neighbors facilitated seed yield of native populations of B. nigra (Fig. 2). For the invasive populations of $B$. nigra, the legume neighbors competitively suppressed seed yield, while the grass neighbors had no significant effect on seed yield (Fig. 2). Conspecific plant neighbors generally competitively suppressed seed yields by both native and invasive populations of $B$. nigra under either level of insect damage (Fig. 2). Plant neighbor treatments and level of herbivore damage influenced production of plant biomass by the invasive and native populations of B. nigra in similar fashion to the seed yields (Fig. 2). The expression of plant height by invasive populations of $B$. nigra was either facilitated or unaffected by plant neighbors under either level of herbivore damage, while that by native populations of $B$. nigra was suppressed by the plant neighbors under reduced level of damage and facilitated or unaffected under ambient level of herbivore damage (Fig. 2). Our 

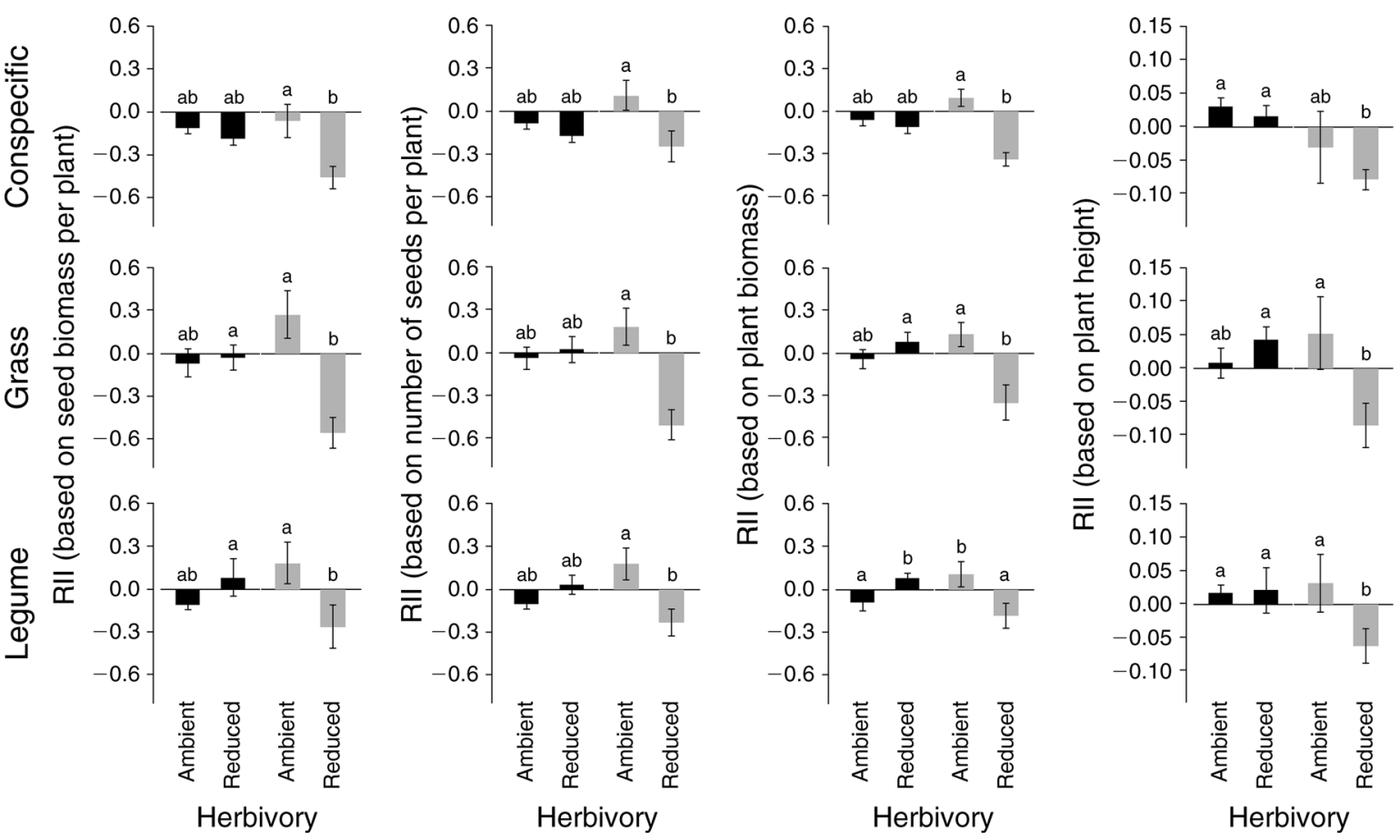

FIG. 2. Mean $( \pm \mathrm{SE})$ relative interaction intensity (RII) indicating competitive suppression or facilitation of phenotypic trait expressions by invasive (black bars) and native (gray bars) populations of Brassica nigra by their plant neighbors under two levels of insect herbivore damage: ambient herbivory vs. reduced herbivory. The plant neighbors were conspecific or heterospecific (grass and legume). Means with the same letter are not significantly different from each other $(P>0.05)$.

finding that, in general, the plant neighbors facilitated or competitively suppressed the native populations of $B$. nigra under ambient vs. reduced levels of herbivore damage, respectively, lends support to the stressgradient hypothesis.

Whereas we cannot conclude from the current experiment through which mechanism, resistance or tolerance, insect herbivores mediated the different competitive and facilitative responses of native and invasive populations of $B$. nigra to their plant neighbors, our results show striking effects of insect herbivores as mediators of the outcome of such responses. That such effects differ between native and invasive populations of $B$. nigra is noteworthy. In $B$. nigra, resistance to generalist insect herbivores is positively correlated with increased sinigrin content (Lankau and Kliebenstein 2009), and sinigrin also mediates competitive interactions between $B$. nigra and conspecific or heterospecific plant neighbors (Lankau and Kliebenstein 2009, Lankau et al. 2011). Specifically, high sinigrin-expressing B. nigra genotypes suppress heterospecific plant neighbors more than low sinigrin-expressing B. nigra genotypes (Lankau and Strauss 2007, Lankau and Kliebenstein 2009). Brassica nigra genotypes that express low amounts of sinigrin have been reported to be stronger intraspecific competitors than B. nigra genotypes that express high amounts of sinigrin (Lankau and Strauss 2007). We have previously reported that invasive populations of $B$. nigra expressed higher concentrations of sinigrin than native populations of $B$. nigra, possibly as a result of selection by different herbivore species assemblages between the invasive and native ranges of $B$. nigra (Oduor et al. 2011). Hence, differential herbivory pressure in either range might alter the nature of competitive interactions between $B$. nigra and its plant neighbors via altered expressions of sinigrin. In similar studies, invasive populations of Solidago canadensis (Yuan et al. 2012) and Centaurea maculosa (Ridenour et al. 2008) that expressed comparatively high concentrations of allelochemicals had higher competitive effects on heterospecific neighbors than native populations of those invasive plant species. Some investigators have hypothesized that damage by insect herbivores can induce expression of a high level of tolerance, leading to increased rates of resource use in certain plant species (Callaway et al. 1999, Siemens et al. 2003, Jones et al. 2006). This suggests a positive correlation between tolerance of herbivore damage and competitive ability for those species. In fact, it has been reported that invasive populations of $C$. maculosa that had higher tolerance of herbivore damage also had higher competitive ability than native populations of $C$. maculosa that had lower tolerance (Ridenour et al. 2008). Our current results indicate that plant neighbors increased (i.e., facilitated) tolerance of herbivore damage by the native populations of $B$. nigra. This is because the native populations of $B$. nigra had higher levels of phenotypic expression of growth and reproductive traits under the 


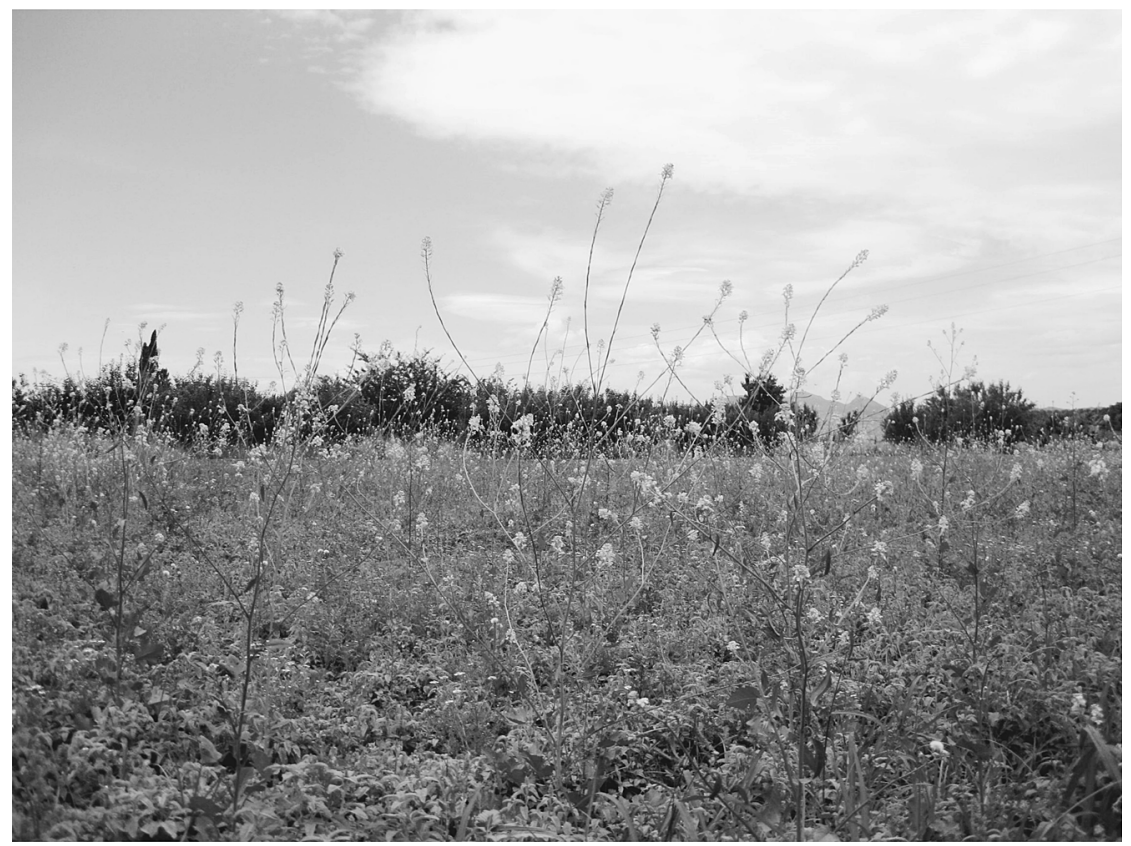

Plate 1. Invasive and native populations of Brassica nigra (flowering in foreground) grown in a common-garden field experiment in Granada, southeastern Spain. Photo credit: A. M. O. Oduor.

ambient level of insect herbivore damage and in the presence of plant neighbors (Fig. 2). It is plausible that ambient levels of herbivore damage induced high expression of tolerance by the native populations, leading to increased acquisition of growth resources, and that plant neighbors facilitated the availability of such resources. Environmental stress (e.g., low moisture availability) can reduce the ability of a plant to tolerate herbivore damage (Rand 2004). Hence, plant neighbors that mitigate such stress (e.g., through shading to reduce moisture loss) can increase a focal plant's tolerance of herbivore damage (Rand 2004). The present study did not isolate the growth resources (nutrients, water, and light) at the center of competitive and facilitative interactions between the experimental plants. An interesting avenue for further studies is to identify which of these growth resources affect(s) competitive and facilitative interactions in the present study system.

We have previously reported that native populations of $B$. nigra expressed higher tolerance of, and lower resistance to, damage, by insect herbivores than invasive populations of B. nigra (Oduor et al. 2011). Those results likely hold true in the current study, because the native populations of $B$. nigra seemed to express higher tolerance under ambient levels of insect herbivore damage, as just discussed. Together with the previous results, the current results indicate that higher tolerance of herbivore damage by native populations of $B$. nigra, which is likely facilitated by plant neighbors, may enable the native populations to cope with intense damage caused by high species diversity of generalist and specialist insect herbivores in the native range. Because the native ranges of invasive plant species harbor a more diverse community of generalist and specialist herbivores than the invasive ranges (Liu and Stiling 2006), tolerance may be a more suitable strategy than resistance for the native populations of invasive plant species to cope with damage by the herbivores (Jokela et al. 2000). As the diversity of herbivores increases, resistance is likely to be less effective, as the plant would need to produce a wide variety of costly defense compounds to match the different herbivore species. On the other hand, tolerance is likely to be equally effective against generalist and specialist herbivores, with its relative value determined by the total amount of herbivore damage received.

Our qualitative comparison of herbivore species identities between the current native range experimental site in Granada (Spain) vs. an exotic range experimental site at the University of California-Davis (USA), revealed that $B$. nigra interacts with different community assemblages of generalist and specialist herbivores in these two sites. In Granada, B. nigra interacted with 16 generalist and 12 specialist herbivores, while in California, B. nigra interacted with 9 generalist and 5 specialist herbivores (Appendices $\mathrm{C}$ and $\mathrm{D}$ ). Of these, there were only three generalist and three specialist herbivores in common between the two sites (Appendices $\mathrm{C}$ and $\mathrm{D})$. These data on differential herbivore community assemblages in the native vs. exotic range sites support the hypothesis that the striking differences between native and invasive populations of $B$. nigra in phenotypic expressions of the growth and reproductive traits noted here might be the result of differential 
herbivore selection pressures in both exotic and native ranges of $B$. nigra.

Because invasive plant species often interact with different plant community assemblages in their exotic vs. native ranges, which potentially leads to different evolutionary trajectories in either range (Callaway and Aschehoug 2000, Hierro et al. 2005), a major challenge remains with respect to choosing appropriate heterospecific plant neighbors against which to test postintroduction evolution of traits by invasive plants (Bossdorf et al. 2005). While it has been suggested that use of conspecific plant neighbors alone might help to overcome this challenge, many invasive plant species interact with both conspecific and heterospecific plant neighbors in either range (Bossdorf et al. 2005). Hence, a more thorough insight into post-introduction trait evolution by invasive plants can be gained from experiments that use both conspecific and heterospecific plant neighbors.

It would be of interest to know whether the patterns we have observed in the current native range experiment would hold true for a similar experiment conducted in the invasive range of $B$. nigra. We are likely to gain more insight into the ecological and evolutionary processes underlying plant invasions by studying invasive and native populations of plant species in both their native and exotic ranges (Hierro et al. 2005). Neverthless, such biogeographical studies have to overcome various challenges including those of ethics, in which there is a need to prevent the risk of introducing novel genotypes of invasive plant species to a new range (Hierro et al. 2005).

The other studies that have tested post-introduction evolutionary changes in phenotypic trait expression by invasive plant species in the presence of plant neighbors (although without manipulating levels of herbivore damage) have found mixed results. Similar growth between invasive and native populations was found in Eschscholzia californica (Leger and Rice 2003), Hypericum perforatum (Vilà et al. 2003), Silene latifolia (Blair and Wolfe 2004), Lepidium draba (McKenney et al. 2007) and Centaurea maculosa (He et al. 2009). In contrast, invasive populations of Sapium sebiferum (Zou et al. 2008a) and C. maculosa (Ridenour et al. 2008) grew larger than native populations of the same plant species. Native populations of Alliaria petiolata had greater growth than invasive populations of that plant species (Bossdorf et al. 2004a). Mixed results are also found for resistance to, and tolerance of, herbivory by native and invasive populations of various plant species (e.g., Bossdorf et al. 2004b, Joshi and Vrieling 2005, Stastny et al. 2005, Zou et al. 2008b, Oduor et al. 2011, Wang et al. 2012). Taken together, some of these conflicting phenotypic expressions of growth, reproductive, and defensive traits between invasive and native populations of various plant species may be the result of differential selection pressures exerted by both herbi- vores and plant neighbors in the exotic and native ranges.

Results from the present study are a significant first step toward an understanding and prediction of how altered level of herbivore damage can influence pairwise interactions between invasive and native populations of plant species and their plant neighbors. In natural plant communities, direct interactions between two neighboring plants may be highly modified by indirect or diffuse effects of a third plant (Levine 1999, Callaway and Pennings 2000). For example, the direct competitive effect of one plant species on a second plant species (i.e., a focal plant species) can be weakened by the indirect facilitative effect of a third plant species acting on the focal plant species (Levine 1999, Callaway and Pennings 2000). This can occur when the third plant species suppresses the competitive effect of the first plant species on the focal plant species (Levine 1999, Callaway and Pennings 2000). Therefore, results from experimental studies of pairwise interactions between plants may not provide a full understanding of how plant species interact within communities (Callaway and Pennings 2000). An advanced understanding of herbivore-mediated interactions between invasive and native populations of plants and their plant neighbors will be gained from future experiments similar to the one we report here, which manipulate the presence and absence of two or more plant neighbors.

Biological invasions inherently involve demographic processes that ultimately lead to changes in population growth rates (Strauss et al. 2006, Leger and Espeland 2010). In the present study, we have inferred postintroduction evolutionary changes in growth and reproductive traits of invasive and native populations of $B$. nigra as a consequence of altered interactions with insect herbivores and plant neighbors. However, how such putatively evolved trait differences affect demographic processes and population growth rates of the respective populations remains unknown. To date, little is known of how post-introduction trait evolution by invasive plant species can in turn influence demographic processes, and ultimately, population dynamics of such plant species (Hahn et al. 2012). Future studies that employ life table response experiments (LTRE) (e.g., Elderd and Doak 2006, Dauer et al. 2012, Hahn et al. 2012) will help elucidate the role of post-introduction trait evolution in influencing demographic parameters and population growth rates of invasive plant species.

In conclusion, our results suggest that $B$. nigra may have experienced post-introduction evolution in traits that influence the outcomes of its interactions with herbivores and plant neighbors, and that a change in herbivory pressure between exotic and native ranges of $B$. nigra may have catalyzed such trait evolution. In many terrestrial ecosystems, herbivore-mediated interactions between plants are one of the many processes shaping plant communities. Only by examining multiple interactions can we gain additional insights into the 
ecological and evolutionary processes underlying plant invasions.

\section{ACKNOWLEDGMENT}

We thank Instituto de Formación Agraria y Pesquera (IFAPA-Camino de Purchil, Granada) for allowing us to perform this experiment in their garden. We also thank Rick Lankau, Mirka Macel, and IPK (Germany) for providing Brassica nigra seeds. We are grateful to two anonymous reviewers for very helpful comments on a previous version of the manuscript. This study was supported by a Banco Bilbao Vizcaya Argentaria grant to J. M. Gómez and Sharon Y. Strauss (BBVA-BIOCON06/064), a Consolider-Ingenio grant (CSD2008-00040), and Junta de Andalucía PAI (RNM 220).

\section{Literature Cited}

Agrawal, A. A., A. P. Hastings, M. T. J. Johnson, J. L. Maron, and J. P. Salminen. 2012. Insect herbivores drive real-time ecological and evolutionary change in plant populations. Science 338:113-116.

Armas, C., R. Ordiales, and F. I. Pugnaire. 2004. Measuring plant interactions: a new comparative index. Ecology 85: 2682-2686.

Bates, D. 2011. Mixed models in R using the lme4 package. Part 5: Generalized linear mixed models. University of Wisconsin, Madison, Wisconsin, USA. http://lme4.r-forge. r-project.org/

Bates, D., M. Mächler, and B. Bolker. 2012. Fitting linear mixed-effects models using lme4. Journal of Statistical Software VV:1-9.

Bell, D. T., and C. H. Muller. 1973. Dominance of California annual grasslands by Brassica nigra. American Midland Naturalist 90:277-299.

Bertness, M., and R. M. Callaway. 1994. Positive interactions in communities. Trends in Ecology and Evolution 9:191-193.

Blair, A. C., and L. M. Wolfe. 2004. The evolution of an invasive plant: an experimental study with Silene latifolia. Ecology 85:3035-3042.

Blossey, B., and R. Nötzold. 1995. Evolution of increased competitive ability in invasive nonindigenous plants: a hypothesis. Journal of Ecology 83:887-889.

Bossdorf, O., H. Auge, L. Lafuma, W. E. Rogers, E. Siemann, and D. Prati. 2005. Phenotypic and genetic differentiation between native and introduced plant populations. Oecologia 144:1-11.

Bossdorf, O., D. Prati, H. Auge, and B. Schmid. 2004a. Reduced competitive ability in an invasive plant. Ecology Letters 7:346-353.

Bossdorf, O., S. Schröder, D. Prati, and H. Auge. $2004 b$. Palatability and tolerance to simulated herbivory in native and introduced populations of Alliaria petiolata (Brassicaceae). American Journal of Botany 91:856-862.

Buckley, Y. M., et al. 2003. Are invasives bigger? A global study of seed size variation in two invasive shrubs. Ecology 84:1434-1440.

Callaway, R. M., and E. T. Aschehoug. 2000. Invasive plants versus their new and old neighbors: a mechanism for exotic invasion. Science 290:521-523.

Callaway, R. M., T. H. DeLuca, and W. M. Belliveau. 1999. Biological-control herbivores may increase competitive ability of the noxious weed Centaurea maculosa. Ecology 80: 1196-1201.

Callaway, R. M., J. Kim, and B. E. Mahall. 2006. Defoliation of Centaurea solstitialis stimulates compensatory growth and intensifies negative effects on neighbors. Biological Invasions 8:1389-1397.

Callaway, R. M., and S. C. Pennings. 2000. Facilitation may buffer competitive effects: indirect and diffuse interactions among salt marsh plants. American Naturalist 156:416-424.
Callaway, R. M., and L. R. Walker. 1997. Competition and facilitation: a synthetic approach to interactions in plant communities. Ecology 78:1958-1965.

Dauer, J. T., P. B. McEvoy, and J. Van Sickle. 2012. Controlling a plant invader by targeted disruption of its life cycle. Journal of Applied Ecology 49:322-330.

Elderd, B. D., and D. F. Doak. 2006. Comparing the direct and community-mediated effects of disturbance on plant population dynamics: flooding, herbivory and Mimulus guttatus. Journal of Ecology 94:656-669.

Feeny, P. P., and L. Rosenberry. 1982. Seasonal variation in the glucosinolate content of North American Brassica nigra and Dentaria species. Biochemical Systematics and Ecology 10: $23-32$.

Goergen, E. M., E. A. Leger, and E. K. Espeland. 2011. Native perennial grasses show evolutionary response to Bromus tectorum (Cheatgrass) invasion. PLoS ONE 6(3):e18145.

Hahn, M. A., Y. M. Buckley, and H. Müller-Scharer. 2012. Increased population growth rate in invasive polyploid Centaurea stoebe in a common garden. Ecology Letters 15: 947-954.

He, W. M., Y. Feng, W. M. Ridenour, G. C. Thelen, J. L. Pollock, A. Diaconu, and R. M. Callaway. 2009. Novel weapons and invasion: biogeographic differences in the competitive effects of Centaurea maculosa and its root exudate (+/-)-catechin. Oecologia 159:803-815.

Hierro, J. L., J. L. Maron, and R. M. Callaway. 2005. A biogeographical approach to plant invasions: the importance of studying exotics in their introduced and native range. Journal of Ecology 93:5-15.

Johnson, M. T. J., R. Dinnage, A. Y. Zhou, and M. D. Hunter. 2008. Environmental variation has stronger effects than plant genotype on competition among plant species. Journal of Ecology 96:947-955.

Jokela, J., P. Schmid-Hempel, and M. C. Rigby. 2000. Dr. Pangloss restrained by the Red Queen - steps towards a unified defence theory. Oikos 89:267-274.

Jones, T., S. Kulseth, K. Mechtenberg, C. Jorgenson, M. Zehfus, P. Brown, and D. H. Siemens. 2006. Simultaneous evolution of competitiveness and defense: induced switching in Arabis drummondii. Plant Ecology 184(2):245-257.

Joshi, J., and K. Vrieling. 2005. The enemy release and EICA hypothesis revisited: incorporating the fundamental difference between specialist and generalist herbivores. Ecology Letters 8:704-714.

Lankau, R. A. 2008. A chemical trait creates a genetic trade-off between intra- and interspecific competitive ability. Ecology 89:1181-1187.

Lankau, R. A., and D. J. Kliebenstein. 2009. Competition, herbivory and genetics interact to determine the accumulation and fitness consequences of a defence metabolite. Journal of Ecology 97:78-88.

Lankau, R. A., and S. Y. Strauss. 2007. Mutual feedbacks maintain both genetic and species diversity in a plant community. Science 317:1561-1563.

Lankau, R. A., and S. Y. Strauss. 2008. Community complexity drives patterns of natural selection on a chemical defense of Brassica nigra. American Naturalist 171:150-161.

Lankau, R. A., E. Wheeler, A. E. Bennett, and S. Y. Strauss. 2011. Plant-soil feedbacks contribute to an intransitive competitive network that promotes both genetic and species diversity. Journal of Ecology 99:176-185.

Leger, E. A., and E. K. Espeland. 2010. Coevolution between native and invasive plant competitors: implications for invasive species management. Evolutionary Applications 3: $169-178$.

Leger, E. A., and K. J. Rice. 2003. Invasive California poppies (Eschscholzia californica Cham.) grow larger than native individuals under reduced competition. Ecology Letters 6: 257-264. 
Levine, J. M. 1999. Indirect facilitation: evidence and predictions from a riparian community. Ecology 80:1762-1769.

Liu, H., and P. Stiling. 2006. Testing the enemy release hypothesis: a review and meta-analysis. Biological Invasions 8:1535-1545.

Louda, S. M., K. H. Keeler, and R. D. Holt. 1990. Herbivore influence on plant performance and competitive interactions. Pages 414-437 in J. B. Grace and D. Tilman, editors. Perspectives on plant competition. Academic Press, Oxford, UK.

Maron, J. L., M. Vilà, R. Bommarco, S. Elmendorf, and P. Beardsley. 2004. Rapid evolution of an invasive plant. Ecological Monographs 74:261-280.

Maschinski, J., and T. G. Whitham. 1989. The continuum of plant responses to herbivory: the influence of plant association, nutrient availability, and timing. American Naturalist 134:1-19.

McKenney, J. L., M. G. Cripps, W. J. Price, H. L. Hinz, and M. Schwarzlaender. 2007. No difference in competitive ability between invasive North American and native European Lepidium draba populations. Plant Ecology 193:293-303.

Müller-Scharer, H., U. Schaffner, and T. Steinger. 2004. Evolution in invasive plants: implications for biological control. Trends in Ecology and Evolution 19:417-422.

Oduor, A. M. O., R. A. Lankau, S. Y. Strauss, and J. M. Gomez. 2011. Introduced Brassica nigra populations exhibit greater growth and herbivore resistance but less tolerance than native populations in the native range. New Phytologist 191:536-544.

R Development Core Team. 2009. A language and environment for statistical computing. R Foundation for Statistical Computing, Vienna, Austria.

Rand, T. A. 2004. Competition, facilitation, and compensation for insect herbivory in an annual salt marsh forb. Ecology 85 : 2046-2052.

Ridenour, W. M., J. M. Vivanco, Y. Feng, J. I. Horiuchi, and R. M. Callaway. 2008. No evidence for trade-offs: Centaurea plants from America are better competitors and defenders. Ecological Monographs 78:369-386.

Siemens, D. H., H. Lischke, N. Maggiulli, S. Schürch, and B. A. Roy. 2003. Cost of resistance and tolerance under competition: the defense-stress benefit hypothesis. Evolutionary Ecology 17:247-263.

Stastny, M., U. Schaffner, and E. Elle. 2005. Do vigour of introduced populations and escape from specialist herbivores contribute to invasiveness? Journal of Ecology 93:27-37.

Strauss, S. Y., L. A. Lau, and S. P. Carroll. 2006. Evolutionary responses of natives to introduced species: what do intro- ductions tell us about natural communities? Ecology Letters 9:354-371.

Thelen, G. C., J. M. Vivanco, B. Newingham, W. Good, H. P. Bais, P. Landres, A. Caesar, and R. M. Callaway. 2005. Insect herbivory stimulates allelopathic exudation by an invasive plant and the suppression of natives. Ecology Letters 8:209-217.

Vellend, M. 2006. The consequences of genetic diversity in competitive communities. Ecology 87:304-311.

Vilà, M., A. Gomez, and J. L. Maron. 2003. Are alien plants more competitive than their native conspecifics? A test using Hypericum perforatum L. Oecologia 137:211-215.

Wang, Y., E. Siemann, G. S. Wheeler, L. Zhu, X. Gu, and J. Ding. 2012. Genetic variation in anti-herbivore chemical defences in an invasive plant. Journal of Ecology 100:894 904

Westman, A. L., and S. Kresovich. 1999. Simple sequence repeat (SSR)-based marker variation in Brassica nigra genebank accessions and weed populations. Euphytica 109: 85-92.

Whitney, K. D., and C. A. Gabler. 2008. Rapid evolution in introduced species, 'invasive traits' and recipient communities: challenges for predicting invasive potential. Diversity and Distributions 14:569-580.

Willis, C. G., M. T. Brock, and C. Weinig. 2010. Genetic variation in tolerance of competition and neighbor suppression in Arabidopsis thaliana. Journal of Evolutionary Biology 23(7):1412-1424.

Yuan, Y., B. Wang, S. Zhang, J. Tang, C. Tu, S. Hu, J. H. W. Yong, and X. Chen. 2012. Enhanced allelopathy and competitive ability of invasive plant Solidago Canadensis in its introduced range. Journal of Plant Ecology. http://dx.doi. org/10.1093/jpe/rts/033

Zou. J., W. E. Rogers, and E. Siemann. 2008a. Increased competitive ability and herbivory tolerance in the invasive plant Sapium sebiferum. Biological Invasions 10:291-302.

Zou, J., E. Siemann, W. E. Rogers, and S. J. DeWalt. $2008 b$. Decreased resistance and increased tolerance to native herbivores of the invasive plant Sapium sebiferum. Ecography 31:663-671.

Züst, T., C. Heichinger, U. Grossniklaus, H. Harrington, D. J. Kliebenstein, and L. A. Turnbull. 2012. Natural enemies drive geographic variation in plant defenses. Science 338: $116-119$

Zuur, A. F., E. N. Ieno, N. J. Walker, A. A. Saveliev, and G. M. Smith. 2009. Mixed effects models and extensions in ecology with R. First edition. Springer, New York, New York, USA.

\section{Supplemental Material}

\section{Appendix A}

A table showing a linear mixed-effects model (LMM) fitted to test for effects of invasive status, insecticide, and their interaction on percentage leaf damage on invasive and native populations of Brassica nigra (Ecological Archives E094-211-A1).

\section{Appendix B}

A figure showing mean $( \pm \mathrm{SE})$ percentage leaf damage on invasive and native populations of Brassica nigra treated with and without an insecticide (Ecological Archives E094-211-A2).

\section{Appendix C}

A table showing herbivores noted on invasive and native populations of Brassica nigra in the present native range experimental site in Granada, Spain (Ecological Archives E094-211-A3).

\section{Appendix D}

A table showing herbivores noted on Brassica nigra in a common-garden experimental site on the campus of the University of California-Davis, USA (Ecological Archives E094-211-A4). 